Published in final edited form as:

Crit Care Med. 2016 March ; 44(3): e168-e173. doi:10.1097/CCM.0000000000001431.

\title{
Critical Care Implications of the Affordable Care Act
}

\author{
Anjali P. Dogra, MD and \\ Johns Hopkins Medicine \\ Todd Dorman, MD, FCCM \\ Johns Hopkins Medicine
}

\begin{abstract}
Objectives-To provide an overview of key elements of the Affordable Care Act (ACA). To evaluate ways in which the ACA will likely impact the practice of critical care medicine. To describe strategies that may help health systems and providers effectively adapt to changes brought about by the ACA.
\end{abstract}

Data Sources and Synthesis-Data sources for this concise review include search results from the PubMed and Embase databases, as well as sources relevant to public policy such as the text of the Patient Protection and Affordable Care Act and reports of the Congressional Budget Office (CBO). As all of the ACA's provisions will not be fully implemented until 2019, we also drew upon cost, population and utilization projections as well as the experience of existing statebased healthcare reforms.

Conclusion-The ACA represents the furthest reaching regulatory changes in the US healthcare system since the 1965 Medicare and Medicaid provisions of the Social Security Act. The ACA aims to expand health insurance coverage to millions of Americans and place an emphasis on quality and cost-effectiveness of care. From models which link pay and performance to those which center on episodic care, the ACA outlines sweeping changes to health systems, reimbursement structures, and the delivery of critical care. Staffing models that include daily rounding by an intensivist, palliative care integration, and expansion of the role of telemedicine in areas where intensivists are inaccessible are potential strategies that may improve quality and profitability of ICU care in the post-ACA era.

\section{Key words for indexing}

health care reform; health care quality; access and evaluation; delivery of health care; health services administration; critical care; health care costs; patient protection and affordable care act; policy

\section{Introduction}

The Affordable Care Act (ACA) consists of two pieces of legislation: the Patient Protection and Affordable Care Act (PPACA), which was signed into law on March 23, 2010; and the Health and Education Reconciliation Act, which was enacted on March 30, 2010 (1, 2). The 
ACA, which was upheld by the United States Supreme Court in the case National Federation of Independent Business v. Sebelius on June 28, 2012, is a complex and multifaceted piece of legislation consisting of 10 separate legislative Titles each with a variety of goals.

This article aims to provide an overview of key elements of this far-reaching legislation, as well as a summary of potential implications that it may have for the ICU including a discussion of ICU care and staffing paradigms that may be best-suited to the evolving payment models brought about by the ACA. The ACA has been challenged numerous times within both the legislative and judicial arms of the federal government and has survived all of those challenges. It appears, at least for now, that the ACA is here to stay. Of course, no one really knows for sure, as a change in party control through the 2016 election could support fresh challenges. Given the act appears stable for now, this article should prove useful to those interested in what the implications of the act may be at the level of the ICU.

The centerpiece of the ACA aims to expand health insurance coverage to cut the number of uninsured in America by more than half. The Congressional Budget Office (CBO) has projected that once all of its provisions have been fully implemented, approximately $94 \%$ of the American population will have health insurance coverage, which represents a 31 million person reduction in the uninsured population (3). Nearly half of this reduction is anticipated to come from expanded Medicaid enrollment with a projected 15 million person increase in Medicaid beneficiaries. Additional mechanisms for expanded health insurance coverage include an employer mandate, setup of health insurance exchanges, subsidies for exchange consumers to buy coverage, and tax credits for small businesses.

\section{Discussion}

\section{The Act and its potential implications in healthcare}

Expansion of Insurance Coverage-While expanded coverage projections estimate a steep reduction in the number of uninsured in America as compared to prior to enactment of the ACA, approximately 24 million people are projected to remain uninsured following its full implementation (3). In addition to expanded health insurance coverage, the ACA also aims to improve fairness, quality and affordability of health insurance coverage, strengthen primary and preventive health care access, and to increase healthcare value, quality and efficiency.

The ACA outlines considerable expansion of federal standards for health insurers which were first introduced as part of the Health Insurance Portability and Accountability Act of $1996(4,5,6)$. These include expansion of coverage of young adults up to 26 years of age under their parents' plans, which since September 2010 has led to coverage of 3.1 million previously uninsured young adults. Provisions have also been made for coverage of clinical preventive benefits, expanded appeals rights when claims are denied, and imposition of a ban on lifetime dollar limits on care coverage (7). This ban on lifetime dollar limits is expected to impact more than 105 million Americans. The ACA additionally imposed a ban on exclusion of coverage on the basis of preexisting conditions. 
Research Funding-ACA provisions may also have a significant impact on research directions. The National Institutes of Health $(\mathrm{NIH})$ funding experienced a 5\% decrease in 2013 compared to 2012, and additional reductions are likely (8). However, the ACA establishes potential increases in funding available for certain types of research. Chief among these is the Patient-Centered Outcomes Research Institute (PCORI), a congressionally funded foundation established within the ACA to increase and guide comparative effectiveness research endeavors (9). The ACA also established the Center for Medicare and Medicaid Innovation (CMMI) providing as much as $\$ 1$ billion in grants for ideas to lower cost and improve care for Medicare and Medicaid enrollees $(10,11)$.

Value-Based Purchasing and Care Quality-Though the ACA was signed into law back in 2010, it has had a multiphase rollout with key elements only taking effect in January of 2014, and all of its provisions will not have taken effect until 2019. With its sweeping aims representing the furthest reaching regulatory changes in the US healthcare system since the 1965 Medicare and Medicaid provisions of the Social Security Act, much remains to be seen as to the implications the ACA will have for patients, providers, hospital systems and the ICU.

Title III of the ACA emphasizes value-based purchasing, a concept formally introduced more than a decade ago through the Hospital Quality Alliance (12). The goal of this element of the ACA is to improve quality, efficiency and overall cost-effectiveness of medical care, which is in direct alignment with the six aims of quality care (safe, effective, patientcentered, timely, efficient, equitable) as defined by the Institute of Medicine (IOM) 2001 Crossing the Quality Chasm report (13).

The Centers for Medicare \& Medicaid Services initiated its web-based quality reporting initiative in 2005, and began penalizing those hospitals that did not submit quality data in 2007 (14). This "pay-for-reporting" model serves as a template for the current value-based purchasing (VBP) reform (10). The VBP ties reimbursement to outcome measures by providing hospitals that meet certain performance standards an incentive, thus trying to establish linkage between outcomes and payment. It is important to recognize that this linkage of reimbursement to outcome may ultimately prove unsuccessful, as a meta-analysis from the London School of Economics evaluated 51 experimental studies of financial incentives and found what was described as "overwhelming evidence" that such incentives may actually encourage people to work less hard, reducing an employee's natural inclination to complete a task and derive pleasure from doing so (15).

Accountable Care Organizations-Despite its flaws the linking of outcome and reimbursement may prove crucial to determining the most efficient and financially solvent ICU care and staffing paradigms in this era of evolving reimbursement models. The ACA's demand for improved quality and cost-effectiveness of care as well as growing needs of a newly insured and aging population, has also led to the development of new health care delivery models, such as the accountable care organization (ACO) and the related bundled payment model. 


\section{Potential ICU implications}

At present, there are a dearth of published manuscripts that describe associations between the ACA and changes in practice. In fact, there are no publications that can establish a cause and effect relationship. The changes being brought forth in some environments may be seen as being caused by pressure from the various components of the ACA, but until these are peer-reviewed and published, they must all be treated with some degree of skepticism. Of course, given the dearth of solid information, the presumed associations are the best evidence that exists at this point in history.

The ACO is a multidisciplinary team of providers employed across one or more hospital systems charged with providing cost-effective care to a defined patient population (16). If successful, the ACO will be able to better manage longitudinal care. From an ICU perspective this opens the opportunity for ICU providers to be more involved in prevention of critical illness as well as post intensive care syndromes. The bundled payment also known as episode-based payment provides a fixed reimbursement rate to one or more hospital systems and multidisciplinary providers on the basis of expected costs for clinically-defined episodes of care (17). Bundling payment may limit the amount available to physicians and non-physician providers thus forcing all providers to reexamine their use of services that range from consultations, to labs, to either unnecessary ICU admissions or lengths of stay. Thus partnerships with primary care and emergency medicine will likely be beneficial in impacting prevention of critical illness and subsequent ICU utilization. It is possible that such an approach could impact requests for ICU beds, increasing systems of care that support the ICU without walls concept.

ICU Costs and Reimbursement-The relatively high cost of ICU care portends these reimbursement models may alter how ICUs are staffed and deliver care. While approximately $10 \%$ of total hospital beds are in the ICU, the cost of care to ICU patients is considerably higher than other patients in the hospital accounting for nearly a quarter of a typical hospital budget (18). The cost of ICU care is $\$ 2000-\$ 3000$ per day at many hospitals, and may be even higher at others $(19,20)$. Nationally ICU care costs $\$ 121$ billion annually or nearly $1 \%$ of the GDP (20).

It is important to note that while the proposed Medicare VBP model is federally budgetneutral, it may not be budget-neutral for individual hospital systems. The VBP program scores hospitals on a variety of measures related to process of care, outcomes and patientcenteredness (21). One percent of the base Medicare Diagnosis-Related Group (DRG) payment to hospitals will initially be withheld and used to then reward the better-performing hospitals (22). This withheld amount, which while billed as an incentive for top-performers, economically amounts to a penalty for the worst-performing hospitals, is planned to increase by $0.25 \%$ annually to reach its maximum of $2 \%$ in 2017 .

The estimated VBP incentive payment for 2013 was $\$ 850$ million, and the loss of payment may have a significant negative impact on those hospitals with low VBP scores (23). This may be magnified if, as expected, commercial payers and Medicaid follow suit. This will likely influence hospital structuring and budgets and consequently those of ICUs moving forward. Thus, an increased focus on quality and safety will drive a need for routine reports 
and dashboards to help providers better manage the resources consumed in an ICU setting while improving outcomes. Institution of processes such as the Choosing Wisely Campaign elements may be critical in avoiding unnecessary care and associated costs.

Providers should be aware that even if their payment is not impacted the resources made available by the institution for nursing, respiratory, physical therapy, etc could be impacted and thus models of care and the outcomes thereof could be altered. For instance, there could be pressure on the present 2:1 paradigm of nurse to patient ratios. Flexibility will be key and research into models that integrate all providers in horizontal and/or vertical systems of care will be required.

ICU Length of Stay and Staffing-Several studies have demonstrated an association between daily rounds by an ICU physician and decreased mortality, hospital costs and complications in patients following major surgery $(24,25)$. A 2002 Meta-analysis of more than 25 studies has also demonstrated this reduction in ICU mortality with daily intensivist physician rounds, and when accounting for case mix, also demonstrated an association with decreased ICU length of stay (26). This positive association with decreased ICU length of stay has since been shown in several other studies $(27,28,29)$.

The potential financial impact of this decreased length of stay can be quite significant. This is not only because the expense of prolonged ICU services may be higher than the reimbursement rates for such a stay, but also because prolonged ICU length of stay has been associated with a number of negative and costly outcomes including higher rates of hospitalrelated complications and infections, delirium, and pressure ulcers $(30,31)$.

In addition to direct patient effects, in the VBP model of reimbursement, these quality indicators will likely gain even more financial importance. And reduction of length of stay in the disproportionately costly ICU could increase overall profitability to the hospital system and perhaps even providers in the bundled payment model. These forces should lead to the examination of alternative models that could include more active roles for ethics and palliative care and ICU-based hospice environments.

ICU Utilization and Resource Management-As mentioned, admission to the ICU may be impacted by pressures perceived under global or bundled payment models. Under such models, the institutional costs are likely to be taken off the top and then providers will be paid based upon negotiated rates. Thus, utilization of high cost resources like ICU beds, especially for soft-call admissions will likely be reduced. A parallel reduction in unnecessary testing may also follow. Such changes will likely cause a need for more work to be done to predict and prevent ICU need.

While review of ICU utilization following significant reduction in the number of uninsured persons in the state of Massachusetts indicates utilization rates similar to those prior to this change in insurance coverage rates, one study has projected that by 2020 the demand for intensivist hours may still outpace supply by as much as $22 \%(32,33)$. Thus, an ACOs ability to improve health, at least early in that process may not have a downstream impact on ICU utilization. Only time will tell if such impact will be realized. 
Advances in the realm of telemedicine, that is the exchange of audio and visual information between different locations, may potentially help overcome this shortfall. Both mortality and ICU length of stay have been found to decrease with remote intensivist care when compared to an absence of such input, and continued technologic advancements may potentially increase the effectiveness and feasibility of such a model moving forward $(34,35)$. These systems might not only be utilized to leverage intensivists into units where they do not presently exist, but also to support other provider types in such units. For instance, intensivists could partially oversee the care provided by nurse practitioners and/or physician assistants for care of the less critically ill or serve as the care provider throughout an integrated care delivery network of institutions. In addition, other models that include leveraging other available physician and non-physician resources will also need to be explored.

Demand for not only personnel, however, but also that for material resources, are likely to be outpaced by supply in the coming years. Between 2005 and 2011, the number of drugs that the Federal Drug Administration (FDA) Drug Shortage Program (DSP) reported as being in limited supplies more than quadrupled, and this trend of increasing shortage is anticipated to continue $(36,37)$. From medications needed for rapid sequence intubation (RSI) to those used to treat seizures this list already includes many medications necessary for the care of critically ill patients (38).

Such shortages have been implicated in a number of negative and adverse outcomes including increased medication errors, delayed or cancelled care, decreased patient satisfaction, increased transmission of infection, increased readmission rates and death (39, 40, 41). They have also been associated with an increased cost, and it has been estimated that hospitals already spend more than $\$ 216$ million annually to manage drug shortages with many reporting a need for an increase in staff to carry out this management as well (42). The cost of these drug shortages in the post-ACA era may be significantly higher not only because more drugs are projected to be in limited supply, but also the impact that the associated adverse outcomes and consequent decreased quality of delivered care can have on care reimbursement (43). There have been some recent attempts to pass legislation that would support new drug development, especially, in the anti-infective domain given the progression of resistance.

These resource scarcities may also be magnified by increased utilization of healthcare services by the newly insured population. Uninsured critically ill patients have been found to be more likely to have life support withdrawn, less likely to have invasive procedures, and receive less physical therapy and occupational therapy when compared with their insured counterparts $(44,45,46)$. The anticipated increase in insured patients following full implementation of the ACA may bring with it a need for increased critical care and postcritical illness rehabilitation resources to accommodate these patients. However, these needs may be offset by the ACA's emphasis on improving preventative and primary care services, which may aid in chronic disease management and alter severity of illness at hospital presentation. 
Whether suffering acute coronary syndrome or breast or colorectal cancers, uninsured patients have been found to present at later more severe stages of illness and disease often necessitating more resource-intensive care and suffering worse outcomes (47-50). Review of hospital and ICU service utilization in Massachusetts following a decrease in the uninsured population rate from $9.3 \%$ to $5.1 \%$ found no significant change in ICU admission rates or mortality (51). This decrease in the uninsured population was however associated with increased primary care utilization, decrease in emergency department visits for nonurgent conditions and a decrease in overall hospitalizations for preventable conditions $(52,53,54)$. This is in contrast to the $30 \%$ increase in hospital admissions found following expansion of Medicaid coverage in the state of Oregon through the Oregon Health Insurance Experiment (55). There was also a nearly $10 \%$ increase in discretionary surgery in Massachusetts following insurance coverage expansion (56).

The generalizability of the Massachusetts or Oregon experiences nationally following implementation of the ACA remains questionable. The national population is far more racially and socioeconomically diverse than that in Massachusetts, and at 17\%, the national uninsured rate prior to the ACA was nearly double the starting uninsured rate in Massachusetts (57). Additionally, many ICUs operate at or near capacity, so changes in the number of patients requiring critical care services may not be accurately revealed simply by reviewing ICU utilization. Data regarding severity of illness of the patients requiring critical care services prior to and following significant decreases in the uninsured rate in Massachusetts or elsewhere remains unavailable. Data regarding long-term impact of these measures, particularly in a population where there will be an unprecedented increase in the elderly also remain limited.

The ACA will require providers and health system to increase efforts to eliminate preventable harm. Performance improvement projects within and across health systems will permit benchmarking best practices to occur and if designed around collaborative experience should foster innovation. Such efforts will need to assiduously demonstrate outcomes and assess the impact of implementation of both evidence-based medicine and growing knowledge-base in personalized care.

Aging Population and End of Life Care-Prior to adoption of the ACA persons 65 years or older numbered 39.6 million representing $12.9 \%$ of the US population, however, by 2030, this number is expected to grow to 72.1 million and represent $19 \%$ of the total US population (58). The expansion of this segment of the population is likely to further increase demands on hospital and healthcare systems. Persons aged 65 and older are three times more likely to be discharged from short stay hospitals than persons of all ages, and the average length of hospital stay for these persons is nearly one day longer (59). This excludes admissions with associated mortality.

However, with the cost of chronic critical illness presently in excess of $\$ 20$ billion annually and end of life care for these patients often occurring in the ICU setting it may also be important to explore the role advanced care planning may play in delivery of quality, costeffective care and reimbursement $(60,61)$. There is growing evidence that advanced care planning such as that undertaken in the National Physician Orders for Life Sustaining 
Treatment (POLST) paradigm, which was highlighted in the September 2014 IOM report entitled Dying in America: Improving Quality and Honoring Individual Preferences Near the End of Life may help improve the quality and cost-effectiveness of care provided to patients with poor prognoses (62). The disproportionate utilization of hospital and ICU resources in the last 6 months of life without appreciable change in clinical outcome, has already led some state agencies to use this as a marker of provider performance (63).

Because integration of palliative care into critical care has demonstrated improved family satisfaction and reduction in ICU and hospital length of stay without increasing overall mortality, it may gain additional financial significance under both VBP and bundled payment reimbursement models $(64,65)$. There may also be an expanded role for hospice services under these new payment models, which may actually decrease ICU utilization in patients with poor prognoses (66). It has been demonstrated that amongst patients with poorprognosis cancers, those receiving hospice care had significantly lower rates of ICU admission, invasive procedures at the end of life, and incurred lower total costs in the last year of life compared to those who did not receive hospice care (66). Recently, CMS is considering a proposal to pay for end of life planning discussion. The impact of such a seed change could prove extremely important for ICU utilization. Furthermore, recent attempts to pass legislation to increase funding for the NIH could impact care in subsequent decades.

\section{Conclusion}

Fraught with controversy since its inception, court challenges to elements of the ACA continue in state courts across the country, and it may very well come before the Supreme Court again. However, it is estimated that the ACA has already expanded health insurance coverage to 20 million previously uninsured Americans, and this number is expected to grow in the coming years (67). Additionally, VBP, ACO and bundled payment reimbursement models have already begun. This expansion of health insurance coverage, emphasis on quality and cost-effectiveness, and alteration of reimbursement including reimbursement models which link pay and performance and those which center on episodic care will indelibly alter the delivery of care in hospitals and ICUs across the country for years to come. While staffing models that include daily rounding by an intensivist, palliative care integration, and expansion of the role of telemedicine in areas where intensivists are inaccessible, are examples of some potential strategies to adapt and improve quality and profitability of ICU care in the post-ACA era. The successes and failures of these and other strategies as well as those of the elements of the legislation itself will require further study as the legislation continues to be implemented and its long-term impacts are revealed.

\section{Acknowledgments}

Copyright form disclosures: Dr. Dogra is employed by Johns Hopkins and received support for travel from ACGME (For travel related to ACGME BOD and CLER Committee) and ASA (For travel related to ASA delegation to AMA). Her institution received grant support from the National Institutes of Health (T32). Dr. Dorman served as a board member for the Society of Critical Care Medicine and ACCME, provided expert testimony for several cases, and received support for travel from various entities (for all universities or professional societies overseas). 


\section{References}

1. 2010. Mar 23. The Patient Protection and Affordable Care Act (PPACA), Pub. L. No. 111-148, 124 Stat. 119

2. 2010. Mar 30, Health Care Education and Reconciliation Act, Pub. L. No. 111-152, 124 Stat. 1029

3. Congressional Budget Office. Letter from Douglas W. Elmendorf, Congressional Budget Office Director, to the Honorable Harry Reid, Senate Majority Leader, March 11, 2010. Available online at: http://www.cbo.gov/ftpdocs/113xx/doc11307/Reid_Letter_HR3590.pdf. Accessed December 19, 2013

4. PPACA $\$ 1201$

5. PPACA $\S 1001$

6. Pub. L. No. 104-191 (104th Cong., 2d sess., 1996)

7. Department of Health and Human Services (US). [Accessed December 19, 2013] HealthCare.gov. Understanding the Affordable Care Act: Timeline: What's Changing and When. Available online at: http://www.healthcare.gov/law/timeline/index.html

8. Funding Operations for FY 2013. Washington, DC: National Institutes of Health, U.S. Department of Health and Human Services; 2013. Available online at: http://nexus.od.nih.gov/all/2013/05/08/ funding-operations-for-fy2013/ [Accessed March 22, 2014]

9. Zwelling, L. [Accessed February 25, 2014] Comparative Effectiveness Research: How Can It Change Practice?. Available online at: http://healthaffairs.org.ezproxy.welch.jhmi.edu/blog/ 2011/04/18/comparative-effectiveness-research-how-can-it-change-practice/

10. Doug Trapp. [Accessed February 25, 2014] CMS Offering Physicians Grants for Health Care Innovations. Available online at: http://www.ama-assn.org.ezproxy.welch.jhmi.edu/amednews/ 2011/11/28/gvsc1128.htm

11. Patient Protection and Affordable Care Act, Note 1. Section 3021

12. Jha AK, Li Z, Orav EJ, Epstein AM. Care in U.S. hospitals-the Hospital Quality Alliance Program. New England Journal of Medicine. 2005; 353(3):265-274. [PubMed: 16034012]

13. IOM (Institute of Medicine). Crossing the Quality Chasm: A New Health System for the 21st Century. Washington, D.C: National Academy Press; 2001.

14. Stulberg J. The Physician Quality Reporting Initiative-a gateway to pay for performance: what every health care professional should know. Quality Management in Health Care. 2008; 17(1):2-8. [PubMed: 18204372]

15. When performance-related pay backfires. Available online at: http://www.lse.ac.uk/ newsAndMedia/news/archives/2009/06/performancepay.aspx. Accessed March 23, 2014

16. McClellan M, McKethan AN, Lewis JL, Roski J, Fisher ES. A national strategy to put accountable care into practice. Health Affairs. 2010; 29(5):982-990. [PubMed: 20439895]

17. Cromwell J, Dayhoff DA, Thoumaian AH. Cost savings and physician responses to global bundled payments for Medicare heart bypass surgery. Health Care Finance Rev. 1997; 19(1):41-57.

18. Halpern NA, Pastores SM. Critical care medicine in the United States 2000-2005: an analysis of bed numbers, occupancy rates, payer mix, and costs. Critical Care Medicine. 2010; 38(1):65-71. [PubMed: 19730257]

19. Marik PE. The cost of inappropriate care at the end of life: implications for an aging population. Am J Hosp Palliat Care. 2014 ePub.

20. Noseworthy TW, Konopad E, Shustack A, Johnston R, Grace M. Cost accounting of adult intensive care: methods and human and capital inputs. Critical Care Medicine. 1996; 24(7):11681172. [PubMed: 8674330]

21. Center for Medicare and Medicaid Services. Report to congress: plan to implement a Medicare hospital value-based purchasing program. Baltimore, Maryland: CMS; 2007.

22. Center for Medicare and Medicaid Services. Medicare program; hospital inpatient value-based purchasing program, 76 FR 26, 490. Washington, DC: Government Printing Office (GPO); 2011. Federal register, Vol 76, No. 882011.

23. Kaiser Family Foundation (KFF). Medicare spending and financing: a premier. Menlo Park, CA: KFF; 2011. 
24. Dimick JB, Pronovost PJ, Heitmiller RF, Lipsett PA. Intensive care unit physician staffing is associated with decreased length of stay, hospital cost, and complications after esophageal resection. Critical Care Medicine. 2001; 29(4):753-758. [PubMed: 11373463]

25. Dimick JB, Pronovost PJ, Lipsett PA. The effect of ICU physician staffing and hospital volume on outcomes after hepatic resection. Journal of Intensive Care Medicine. 2002; 17(1):41-47.

26. Pronovost PJ, Angus DC, Dorman T, Robinson KA, Dremsizov TT, Young TL. Physician staffing patterns and clinical outcomes in critically ill patients: a systematic review. Journal of the American Medical Association. 2002; 288(17):2151-2162. [PubMed: 12413375]

27. Reynolds HN, Haupt MT, Thill-Baharozian MC, Carlson RW. Impact of critical care physician staffing on patients with septic shock in a university hospital medical intensive care unit. Journal of the American Medical Association. 1988; 260(23):3446-3450. [PubMed: 3210284]

28. Goh AYT, Lum LCS, Abdel-Latif MEA. Impact of 24 hour critical care physician staffing on casemix adjusted mortality in paediatric intensive care. The Lancet. 2001; 357(9254):445-446.

29. Hawari FI, Al Najjar TI, Zaru L, Al Fayoumee W, Salah SH, Mukhaimar MZ. The effect of implementing high-intensity intensive care unit staffing model on outcome of critically ill oncology patients. Critical Care Medicine. 2009; 37(6):1967-1971. [PubMed: 19384194]

30. Nathens AB, Rivara FP, MacKenzie EJ, et al. The impact of an intensivist-model ICU on traumarelated mortality. Annals of Surgery. 2006; 244(4):545-552. [PubMed: 16998363]

31. Eachempati SR, Hydo LJ, Barie PS. Factors influencing the development of decubitus ulcers in critically ill surgical patients. Critical Care Medicine. 2001; 29(9):1678-1682. [PubMed: 11546964]

32. Lyon SM, Wunsch H, Asch DA, et al. Use of Intensive Care Services and Associated Hospital Mortality After Massachusetts Healthcare Reform. Critical Care Medicine. Nov.2013

33. Angus DC, Kelley MA, Schmitz RJ, White A, Popovich J. Current and projected workforce requirements for care of the critically ill and patients with pulmonary disease: can we meet the requirements of an aging population? Journal of the American Medical Association. 2000; 284(21):2762-2770. [PubMed: 11105183]

34. Breslow MJ, Rosenfeld BA, Doerfler M, et al. Effect of a multiple-site intensive care unit telemedicine program on clinical and economic outcomes: an alternative paradigm for intensivist staffing. Critical Care Medicine. 2004; 32(1):31-38. [PubMed: 14707557]

35. Lilly CM, Cody S, Zhao H, et al. Hospital mortality, length of stay, and preventable complications among critically ill patients before and after tele-ICU reengineering of critical care processes. Journal of the American Medical Association. 2011; 305(21):2175-2183. [PubMed: 21576622]

36. U.S. Food and Drug Administration. [Accessed Jul 1, 2014] Drug Shortages. Available online at: http://www.fda.gov/drugs/drugsafety/DrugShortages/default.htm

37. Rosoff PM, Patel KR, Scales A, et al. Coping with critical drug shortages an ethical approach for allocating scarce resources in hospitals. Arch Internal Medicine. 2012; 172:1494-9.

38. U.S. Food and Drug Administration. [Accessed March 1, 2014] Drug Shortages. Available at: http://www.fda.gov/drugs/drugsafety/DrugShortages/default.htm

39. Mazer-Amirshahi, Maryann; Ali, Pourmand; Steven, Singer; Jesse, Pines; van den Anker, John. Critical Drug Shortages: Implications for Emergency Medicine. Academic Emergency Medicine. 21:704-711. [PubMed: 25039558]

40. Johnson, LA. Associated Press. [Accessed March 15, 2014] Drug Shortage Stirs Fear. Available online at: http://www.ismp.org/sc?k=dssf

41. Cherici, C.; Frazier, J.; Feldman, M., et al. [Accessed July 2, 2014] Navigating Drug Shortages in American Healthcare: A Premier Healthcare Alliance Analysis. Available online at: https:// www.premierinc.com/about/news/11-mar/drug-shortage-white-paper-3-28-11.pdf

42. U.S. Food and Drug Administration. Center for Drug Evaluation and Research. [Accessed July 1, 2014] Approach to Addressing Drug Shortage; Public Workshop. Available online att: http:// www.fda.gov/Drugs/NewsEvents/ucm265968.htm

43. McLaughlin, Milena; Kotis, Despina; Thomson, Kenneth; Harrison, Michael; Fennessy, Gary; Postelnick, Michael; Marc, Scheetz. Effects on Patient Care Caused by Drug Shortages: A Survey. Journal of Managed Care Pharmacy. 19:783-788. [PubMed: 24156647] 
44. Kollef MH. Private attending physician status and the withdrawal of life-sustaining interventions in a medical intensive care unit population. Crit Care Med. 1996; 24:968-975. [PubMed: 8681600]

45. Schnitzler MA, Lambert DL, Mundy LM, Woodward RS. Variations in healthcare measures by insurance status for patients receiving ventilator support. Clin Perform Qual Health Care. 1998; 6:17-22. [PubMed: 10177044]

46. Barnes EF, Frank EM, Montgomery A, Nichols M. Factors predicting rehabilitative service provision in adults with traumatic brain injury. J Med Speech-Lang Pathol. 2005; 13:69-84.

47. Fowler RA, Noyahr LA, Thornton JD, et al. An Official American Thoracic Society systematic review: the association between health insurance status and access, care delivery, and outcomes for patients who are critically ill. American Journal of Respiratory and Critical Care Medicine. 2010; 181(9):1003-1011. [PubMed: 20430926]

48. Brown DL, Schneider DL, Colbert R, Guss D. Influence of insurance coverage on delays in seeking emergency care in patients with acute chest pain. Am J Cardiol. 1998; 82:395-398. [PubMed: 9708677]

49. Ayanian JZ, Kohler BA, Abe T, Epstein AM. The relation between health insurance coverage and clinical outcomes among women with breast cancer. New England Journal of Medicine. 1993; 329:326-331. [PubMed: 8321261]

50. Roetzheim RG, Pal N, Gonzalez EC, Ferrante JM, Van Durme DJ, Krischer JP. Effects of health insurance and race on colorectal cancer treatments and outcomes. American Journal of Public Health. 2000; 90:1746-1754. [PubMed: 11076244]

51. Lyon SM, Wunsch H, Asch DA, et al. Use of Intensive Care Services and Associated Hospital Mortality After Massachusetts Healthcare Reform. Critical Care Medicine. 2014; 42:763-770. [PubMed: 24275512]

52. Long SK, Masi PB. Access and affordability: An update on health reform in Massachusetts, fall 2008. Health Affairs. 2009; 28:w578-587. [PubMed: 19477874]

53. Miller, S. [Accessed October 17, 2013] The effect of insurance on emergency room visits: An analysis of the 2006 Massachusetts health reform. Jun 13. 2012 Available online at: http:// ssrn.com/abstract $=1711502$

54. Kolstad J, Kowalski A. The impact of health care reform on hospital and preventative care: Evidence from Massachusetts. Journal of Public Economics. Dec; 2012 96(11-12):909-929. [PubMed: 23180894]

55. Finkelstein A, Taubman S, Wright B, et al. Oregon Health Study Group. The Oregon Health Insurance Experiment: Evidence from the first year. Quarterly Journal of Economics. 2012; 127:1057-1106. [PubMed: 23293397]

56. Ellimoottil C, Miller S, Ayanian JZ, Miller DC. Effect of Insurance Expansion on Utilization of Inpatient Surgery. JAMA Surgery. 2014 Aug; 149(8):829-36. [PubMed: 24988945]

57. The Kaiser Commission. The Henry J. Kaiser Family Foundation; on Medicaid and the Uninsured:. Massachusetts Health Care Reform: Six Years Later. Available online at: http:// kaiserfamilyfoundation.files.wordpress.com/2013/01/8311.pdf [Accessed March 14, 2014]

58. Department of Health and Human Services; Aging Statistics. Available online at: http:// www.aoa.gov/Aging_Statistics/ [Accessed July 1, 2014]

59. Department of Health and Human Services; Health and Health Care. Available online at: http:// www.aoa.gov/AoARoot/Aging_Statistics/Profile/2013/14.aspx [Accessed July 1, 2014]

60. Nelson JE, Cox CE, Hope AA, Carson SS. Chronic critical illness. American Journal of Respiratory and Critical Care Medicine. 2010; 182(4):446-454. [PubMed: 20448093]

61. Nelson JE, Bassett R, Boss RD, et al. Models for structuring a clinical initiative to enhance palliative care in the intensive care unit: a report from the IPAL-ICU Project (Improving Palliative Care in the ICU). Critical Care Medicine. 2010; 38(9):1765-1772. [PubMed: 20562699]

62. Kelley AS, Ettner SL, Sean Morrison R, Du Q, Wenger NS, Sarkisian CA. Determinants of medical expenditures in the last 6 months of life. Annals of Internal Medicine. 2011; 154(4):235242. [PubMed: 21320939]

63. Higginson IJ, Finlay IG, Goodwin DM, et al. Is there evidence that palliative care teams alter endof-life experiences of patients and their caregivers? Journal of Pain Symptom Management. 2003; 25(2):150-168. [PubMed: 12590031] 
64. Curtis JR, Treece PD, Nielsen EL, et al. Integrating palliative and critical care: evaluation of a quality-improvement intervention. American Journal of Respiratory and Critical Care Medicine. 2008; 178(3):269-275. [PubMed: 18480429]

65. IOM (Institute of Medicine). Dying In America: Improving Quality and Honoring Individual Preferences Near the End of Life. Washing, D.C.: National Academy Press; 2014.

66. Obermeyer Z, Makar M, Abujaber S, Dominici F, Block S, Cutler DM. Association Between the Medicare Hospice Benefit and Health Care Utilization and Costs for Patients With Poor-Prognosis Cancer. JAMA. 2014; 312(18):1888-1896.10.1001/jama.2014.14950 [PubMed: 25387186]

67. Blumenthal D, Collins SR. Health care coverage under the Affordable Care Act -- a progress report. New England Journal of Medicine. 2014; 371:275-281. [PubMed: 24988300] 